\title{
ANÁLISE TEMPORAL DA COBERTURA E USO DA TERRA ATRAVÉS DE OBSERVAÇÕES EM SUPERFÍCIE MODELADA NA APA PETRÓPOLIS, RIO DE JANEIRO
}

\author{
TEMPORAL ANALYSIS OF LAND USE AND LAND COVER THROUGH MODELED SURFACE OBSERVATIONS IN \\ APA PETROPOLIS, RIO DE JANEIRO
}

\begin{abstract}
Bruna Santos Miceli
Universidade Federal do Rio de Janeiro (UFRJ), Rio de Janeiro, RJ, Brasil, bruna.s.miceli@gmail.com

Manoel do Couto Fernandes

Universidade Federal do Rio de Janeiro (UFRJ), Rio de Janeiro, RJ, Brasil, manoel.fernandes@ufrj.br

Alessa Favero Duque Estrada

Universidade Federal do Rio de Janeiro (UFRJ), Rio de Janeiro, RJ, Brasil, alessaduque@gmail.com
\end{abstract}

\begin{abstract}
RESUMO
A ação antrópica vem modificando a paisagem e deixando suas marcas sob a forma de diferentes coberturas e usos da terra. O presente trabalho procurou mostrar essa diversidade, tomando como base o estudo da estrutura horizontal da paisagem, apoiado em análises geoecológicas, com suporte em produtos obtidos através de geoprocessamento, como os Modelos Digitais de Elevação (MDEs). O objetivo principal foi realizar uma análise temporal (entre 1994 e 2007) do uso da terra, utilizando-se de observações em superfície planimétrica e modelada. A área de estudo escolhida foi a APA de Petrópolis, RJ, que se trata de uma unidade de conservação de uso sustentável, localizada em relevo acidentado, o que favoreceu a comparação entre as superfícies. Os resultados mostraram que a APA vem apresentando perda de área de floresta com o aumento da intervenção antrópica, e que essas diferenças são mais pronunciadas quando avaliadas em superfície modelada. Na avaliação da taxa de retração florestal nos 13 anos de análise, a diferença entre as observações em superfície modelada e planimétrica chegou a 0,31 km2/ano, caracterizando um incremento significativo no valor de retração quando avaliado em superfície modelada.
\end{abstract}

Palavras-chave: Cobertura e Uso da terra. Análise espaço temporal. Geoecologia. Modelo digital de elevação. Geoprocessamento.

\begin{abstract}
Human action has been changing the landscape and leaving their mark in the form of different land cover and land uses. This paper seeks to show that diversity, based on the study of horizontal landscape structure, supported by geoecology analyzes supported in geoprocessing products, such as Digital Elevation Models (DEMs). The main purpose was to perform a temporal comparison (between 1994 and 2007) analyzes of land use in planimetric and modeled surface observations. The study area chosen was the APA Petrópolis, RJ, that is a conservation unit of sustainable use, located in rugged relief, that favored the comparison between the surfaces. The results showed that the APA is presenting forest loss with the increase of human interventions, and these differences are bigger when evaluated in modeled surface. In assessing the rate of forest retraction in the 13 years of analysis, the difference between modeled and planimetric surface observations reached $0.31 \mathrm{~km} 2 / \mathrm{year}$, featuring a significant increase in the retraction value calculation when evaluated on modeled surface.
\end{abstract}

Keywords: Cover and land use. Space time analysis. Geoecology. Digital Elevation Model. Geoprocessing.

Artigo recebido para publicação em novembro de 2014

Artigo aceito para publicação em março de 2015

\section{INTRODUÇÃO}


Atualmente, muitos estudos estão sendo feitos em função das consequências da relação do homem com a natureza. A ecologia da paisagem é um estudo que foca nessa temática, em análises da dinâmica da paisagem que mostram, como os diversos componentes presentes nesta, vão se alterando ao longo das décadas pela ocupação humana.

Áreas de Preservação Ambiental, apesar de apresentarem legislação específica que restringe certos tipos de ocupação e uso, ainda sim necessitam de estudos frequentes sobre crescimento e ocupação urbana.

Devido à necessidade de organização e ao processamento de informações, o Geoprocessamento ganha espaço em meio acadêmico, pois se trata de um conjunto de tecnologias que permitem as mais diversas análises espaciais. Para a ciência da Geoecologia, a utilização desses atributos se torna fundamental, uma vez que garantem a operacionalidade das análises complexas inerentes a esse tipo de avaliação integrativa (FERNANDES, 2004).

Seguindo esta lógica, algumas ferramentas como os modelos digitais de elevação (MDEs), fornecem subsídios para o aperfeiçoamento das análises espaciais. Tais modelos levam em consideração a informação altimétrica, ou seja, os dados em 3D, pois parte-se do princípio de que os dados planimétricos (2D), ao não considerarem a variável z (valor altimétrico), podem acabar por se distanciar de um valor mais próximo da realidade. Dessa maneira, os MDEs são utilizados com intuito de modelar o relevo e, assim, alcançar maior confiabilidade com resultados mais próximos à realidade (Figura 1). 


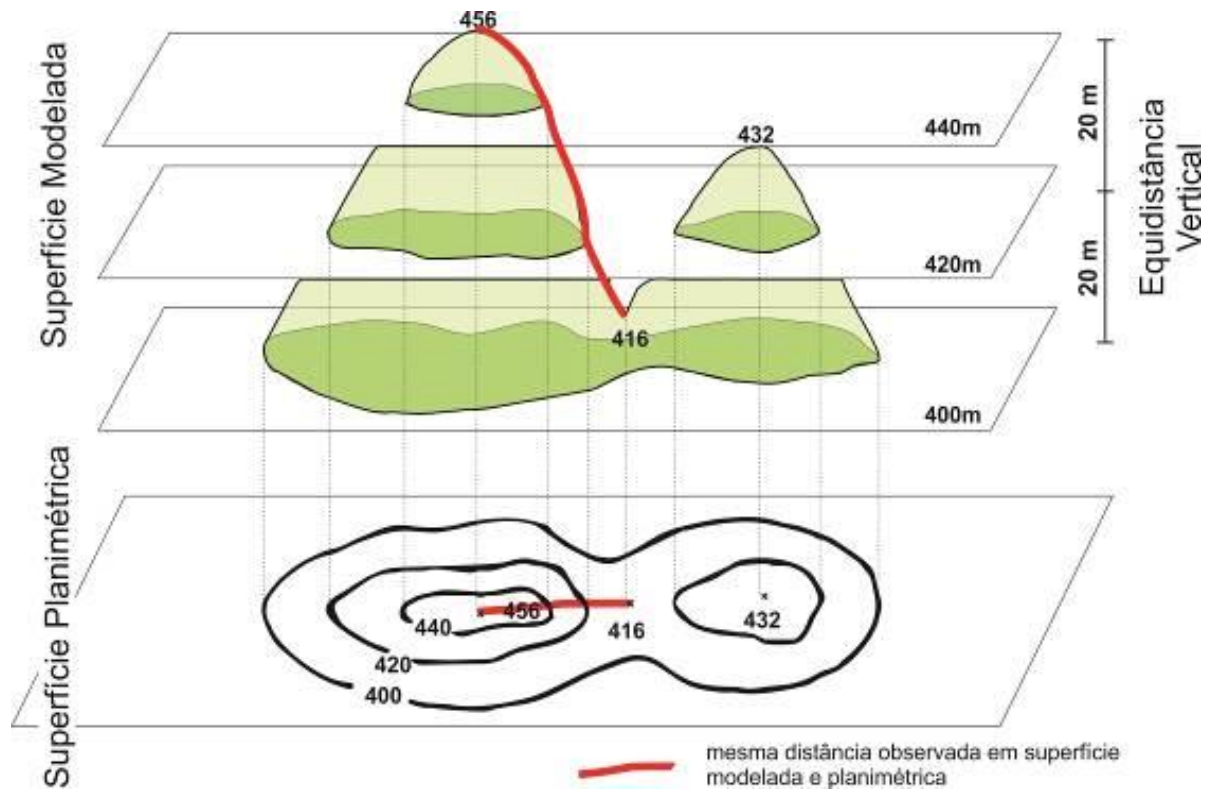

Figura 1. Representação da superfície modelada (real) em cartas topográficas por curvas de nível, apresentando uma distância qualquer em superfície modelada e planimétrica.

Fonte: Adaptado de Menezes \& Fernandes (2013).

Um fator de grande relevância dessa pesquisa é a análise comparativa entre as observações em superfície modelada (SM) e planimétrica (SP), principalmente num relevo bastante movimentado como o da área de estudo, a Área de Proteção Ambiental (APA) de Petrópolis. Uma série de estudos, como os de Fernandes, 2009; Miceli, 2011; Coura, 2012, entre outros mostram que as observações em superfície modelada assumem destacada importância por alcançarem resultados mais favoráveis que as observações em superfície planimétrica, uma vez que levam em consideração a rugosidade do terreno, aproximando-se de resultados mais próximos da realidade.

Outro fator de grande motivação para o desenvolvimento deste trabalho está atrelado ao fato da área de estudo estar inserida em ambientes de bioma Mata Atlântica, que se encontram bastante ameaçadas pela ocupação humana.

Analisar a paisagem da APA Petrópolis torna-se de suma importância aos estudos geoecológicos voltados para dinâmica da vegetação, pois revelam o comportamento das alterações da paisagem dentro de um período de tempo, e também, podem gerar prognósticos da estrutura dessa paisagem e consequentemente de sua funcionalidade. Tais análises contribuirão para estudos que verifiquem o 
grau da conservação da vegetação em Unidades de Conservação. Desta forma, em um primeiro momento, objetivou-se a realização de uma análise horizontal da paisagem, em termos de cobertura e uso da terra, avaliando a dinâmica da paisagem nos anos de 1994 (ABREU, 2010) e 2007 (ZEE, 2009). Em um segundo momento, foi realizada uma análise comparativa entre os resultados das observações em superfície planimétrica e modelada, na escala dos mapeamentos de entrada $(1: 100.000)$.

Por fim, foi criado um mapa de dinâmica da vegetação que revelou a distribuição das classes de cobertura e uso da terra ao longo da área de estudo, analisando a modificação da estrutura da paisagem dos períodos de 1994 e 2007, como subsídio para a geração de uma taxa de retração da vegetação de 1994 a 2007. Todos estes resultados foram avaliados em superfície modelada e planimétrica, procurando evidenciar a importância do uso de informações tridimensionais em análises quantitativas de dinâmica de paisagem.

\section{ÁREA DE ESTUDO}

A APA Petrópolis está situada na porção Centro-Oeste do estado do Rio de Janeiro, na mesorregião metropolitana do Rio de Janeiro, que engloba porções das microrregiões Serrana. Sua área abrange 595,22 km² e se estende, predominantemente, sob grande parte do município de Petrópolis e também pelos municípios de Duque de Caxias, Magé e Guapimirim. Estima-se uma população de 300.000 habitantes, apresentando uma biodiversidade relativamente bem conservada, que tem sido ameaçada por fortes impactos dessa alta densidade populacional (IBAMA, 2007).

A área da APA encontra-se integralmente dentro do Bioma Mata Atlântica. Originalmente, esse bioma recobria cerca de $1.360 .000 \mathrm{~km}^{2}(12 \%$ do território nacional $)$ e atualmente restam poucos remanescentes, com alto índice de fragmentação florestal (BRASIL, 2006). Sua preservação é de vital importância, uma vez que que possui um dos mais altos níveis de biodiversidade do mundo e se estende ao longo da costa brasileira sendo a porção do Brasil que primeiramente foi ocupada (IBAMA, 2007). 
Visto a importância dessa área para a biodiversidade, a APA Petrópolis foi criada em 1982, tornandose a primeira Área de Proteção Ambiental do país com intuito de preservar os remanescentes da Mata Atlântica. A oficialização da APA ocorreu apenas 10 anos depois (1992), sob a administração do antigo IBAMA (Instituto Brasileiro do Meio Ambiente e dos Recursos Naturais Renováveis), atual ICMBio (Instituto Chico Mendes de Conservação da Biodiversidade).

Na figura 2, é apresentada a delimitação e localização da APA Petrópolis, junto às principais unidades de conservação no estado do Rio de Janeiro.

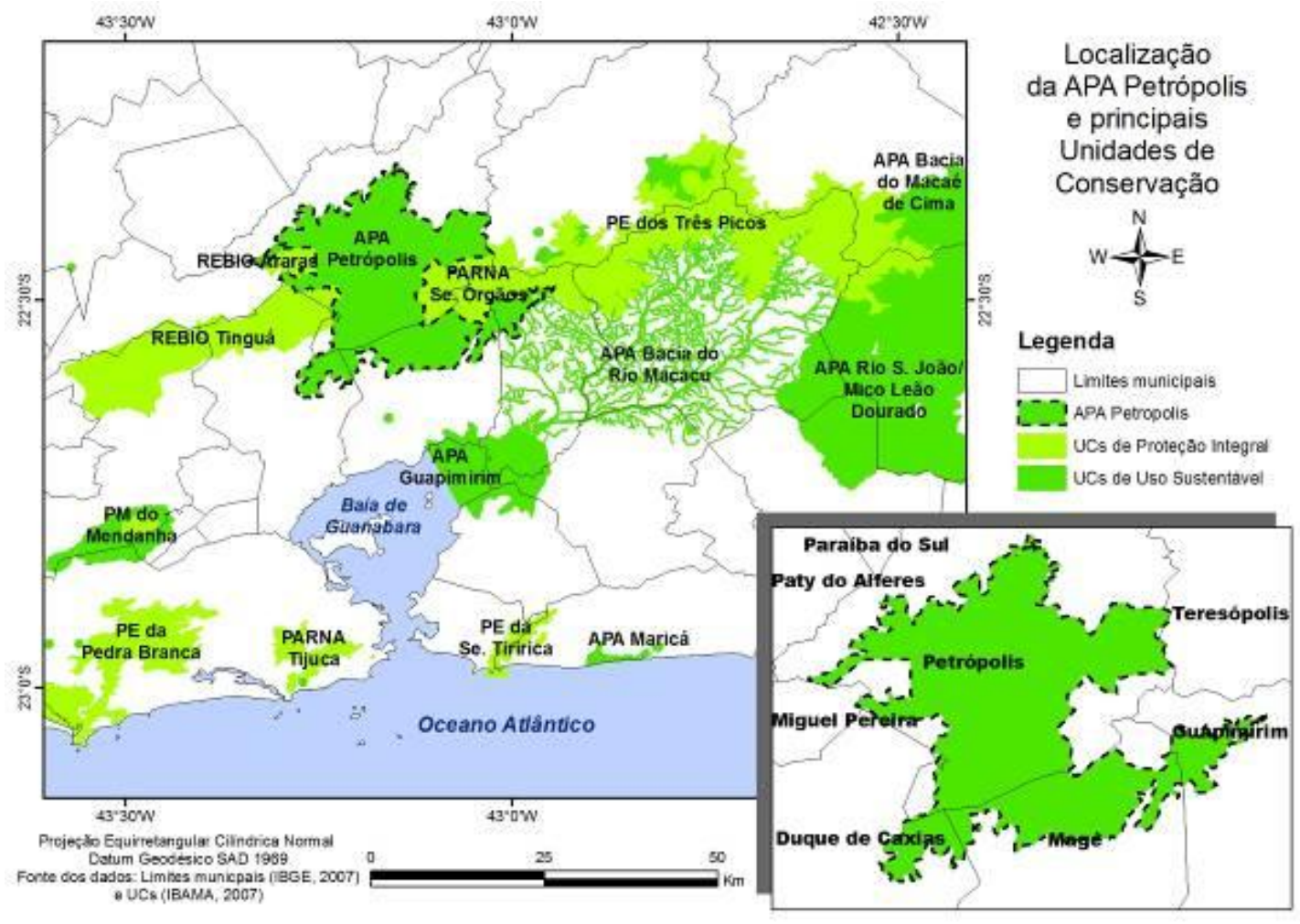

Figura 2. Delimitação da Área de estudo. Fonte: Miceli (2011).

\section{METODOLOGIA}

Uma das bases utilizadas para desenvolver o trabalho foi o mapeamento de cobertura e uso da terra, realizado para o Zoneamento Ecológico Econômico (ZEE) do estado do Rio de Janeiro, para o ano de 2007, na escala de 1:100.000. Neste mapeamento, realizaram-se as seguintes etapas: georreferenciamento (coleta de pontos em campo) das cenas; equalização e mosaico; classificação; 
e edição final. 0 método empregado foi o da classificação orientada a objeto, utilizando imagens do sensor TM do satélite Landsat 5, referentes ao período seco (ZEE, 2009).

Com base no mapeamento de 2007 (ZEE, 2009) foi desenvolvido o de 1994 por Abreu (2010). Entretanto, este autor aponta algumas diferenças nos procedimentos de classificação da imagem de 1994, mesmo tendo utilizado os mesmos métodos para os dois períodos. A fim de reparar as incoerências das classes de usos de 1994 e realizar a comparação com as classes de 2007, foi necessário realizar um refinamento dos dados confrontando as classes entre os dois períodos.

Para as análises em superfície modelada, foi necessário optar por um Modelo Digital de Elevação (MDE). Para efetuar a escolha sobre qual modelo seria considerado como o mais adequado para a área de estudo em questão, tomou-se como base o trabalho de Miceli et al. (2010). Este trabalho teve como objetivo promover uma análise dos modelos dispostos gratuitamente na Internet - ASTER, TOPODATA, SRTM 1, SRTM 4 e EMBRAPA - em termos de precisão e acurácia vertical em áreas de estudo distintas, como a APA Petrópolis e Região Amazônica, na escala de 1:50.000 e 1:100.000, levando em consideração o Padrão de Exatidão Cartográfica (PEC).

Tal análise levou em consideração duas etapas: a primeira foi a aplicação do cálculo do Erro Médio Quadrático e a segunda, se propôs a verificar a tolerância vertical, ambos na escala de 1:100.000. Tanto na primeira quanto na segunda etapa, o modelo TOPODATA se enquadrou com os melhores resultados segundo o PEC, e desta forma, foi o modelo escolhido para ser utilizado como base nas análises propostas em superfície modelada. Na figura 3, pode-se observar o modelo utilizado para a área de estudo. 


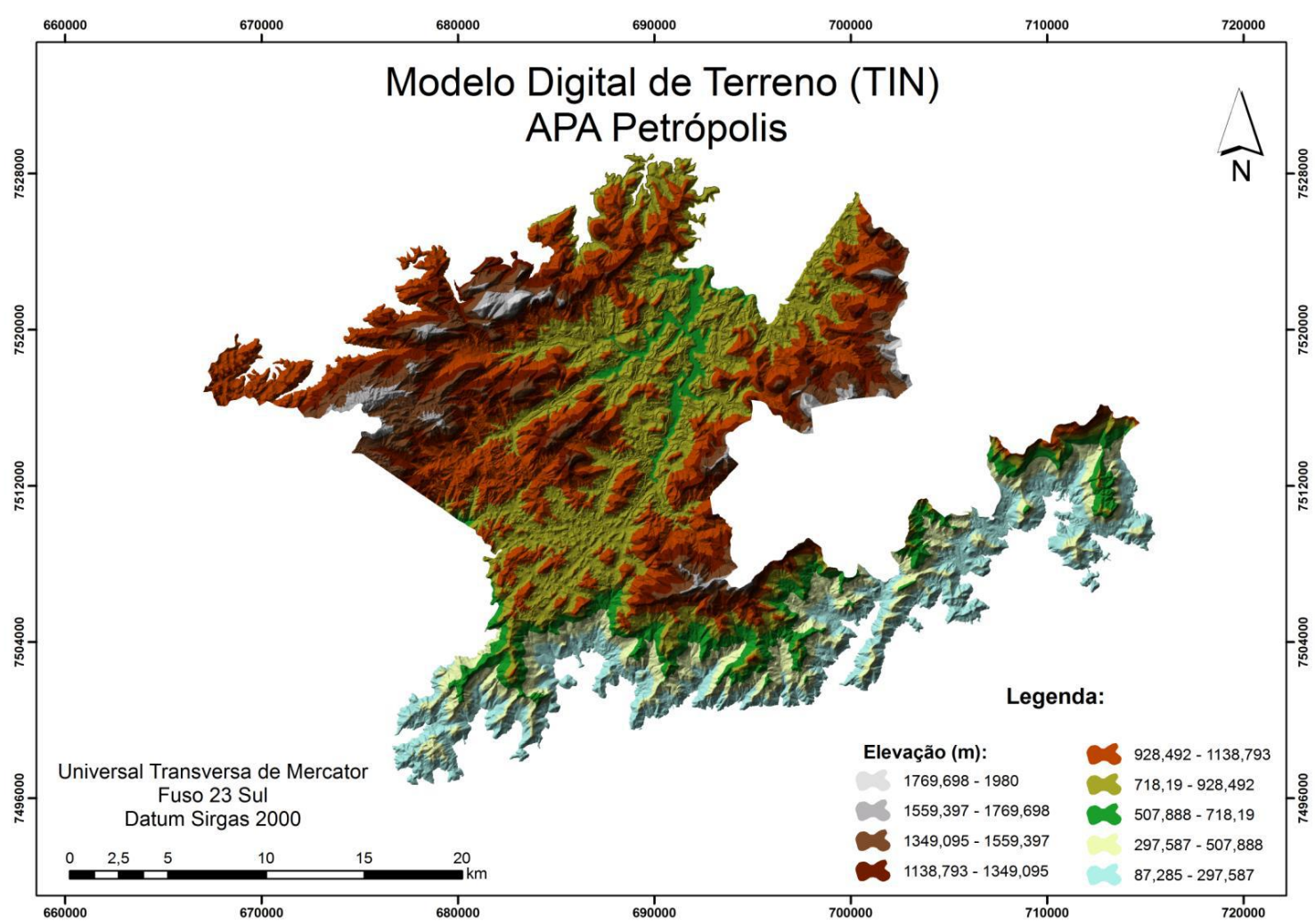

Figura 3. Modelo Digital de Elevação da APA Petrópolis.

Fonte: Miceli (2011).

Em um primeiro momento foi realizado o cálculo de áreas totais de cada cobertura e uso existente nos mapeamentos de 1994 e 2007. Posteriormente foram realizadas as comparações destas classes em superfície modelada e planimétrica. Vale ressaltar que esses cálculos foram realizados a partir do software ArcGIS 9.3. Essa comparação se deu através da diferença percentual entre as duas superfícies tanto para 1994 quanto para 2007, possibilitando observar quais classes possuíam essa diferença acentuada nos períodos propostos.

Por fim, foi calculado a partir do software ArcGIS 9.3, a declividade média para todas as classes, com intuito de verificar se as áreas de maior declividade de fato acentuam a diferença percentual entre as superfícies modelada e planimétrica apontadas na etapa anterior.

Os métodos empregados na segunda etapa são referentes à dinâmica da vegetação, que compreende o resultado da combinação dos dois mapas de cobertura e uso da terra referente aos períodos de 1994 e 2007, de acordo com a metodologia de Fernandes (2004). Essa metodologia subdivide a Dinâmica da 
Vegetação em três grupos, que são eles: Preservação, para toda classe que em 1994 era vegetação e continua até 2007; Não vegetada, para toda classe que em 1994 e 2007 não era vegetação; e por fim, o grupo Retração, para toda classe que em 1994 pertencia a classe vegetação e em 2007 se tornou uma classe não vegetada.

A partir da reorganização das classes, a etapa posterior consistiu na aglutinação de todas as classes para esses três grupos da dinâmica de vegetação, para diagnosticar o quanto de diferença existe entre as observações em superfície modelada e planimétrica, ou seja, o mesmo procedimento realizado no cálculo para cada classe de cobertura e uso. O mapa da dinâmica entre tais períodos também foi criado para mostrar a interação da paisagem de um período ao outro. Para tal, utilizou-se o ArcGIS 9.3. A última fase desse processo referente a dinâmica foi o cálculo da taxa de retração da vegetação ao longo desses 13 anos (1994 a 2007), gerado a partir do subgrupo retração, da dinâmica da vegetação.

\section{RESULTADOS}

Antes de avaliar as diferenças entre observações é importante ressaltar que as mensurações em superfície modelada geram valores maiores que as em superfície planimétrica, pelo fato de levar em consideração o relevo, conforme citado anteriormente. Assim, os resultados apresentados pelas diferenças percentuais de observações em superfície modelada e planimétrica refletem o quanto está sendo negligenciado ao se realizar mensurações em superfície planimétrica.

O primeiro resultado a ser discutido é referente à diferença percentual para cada classe do mapeamento em superfície modelada e planimétrica. As maiores diferenças foram encontradas nas classes que possuem as maiores declividades, que são: Afloramento Rochoso (23,09\%), Agricultura (21,52\%) e Campo de Altitude (15,02\%). As menores diferenças se encontram nas classes de Ocupações Urbanas Média $(3,53 \%)$ e Baixa $(4,33 \%)$, e nulo para a classe ocupação Urbana de Alta Densidade, como observado na figura 4. Esses valores de diferença percentual de 2007 (Figura 5) permaneceram 
acentuados para as classes Afloramento Rochoso (22,96\%) e Campo de Altitude (13,77\%), e mais baixos para as Ocupações Urbanas Média (4,19\%) e Baixa (3,67\%), com o acréscimo da classe Ocupação Urbana de Alta densidade (4,61\%) que em 1994 era nulo. Por fim, duas classes não expressivas foram reflorestamento e solo exposto.

As figuras 6 e 7 apresentam correlações entre as diferenças percentuais de observações em superfície modelada e planimétrica e a declividade média de cada classe de mapeamento de 1994 e 2007, respectivamente. A partir das mesmas, é possível corroborar a ideia de que as maiores diferenças percentuais nas diferentes observações estão relacionadas ao aumento da declividade. Nas figuras 6 e 7, os valores de correlação (R2) são, respectivamente, 0,875 e 0,910 , que são valores correlação muito altos, e pelo fato de serem positivos indicam que o aumento da declividade incide no aumento das diferenças de observações de superfície modelada e planimétrica.

Ainda em relação à análise apresentadas nas figuras 4 e 5, é interessante apontar que a classe Afloramento Rochoso é a que mais apresenta a diferença para os dois períodos, desta forma, essa classe está disposta no mapa (figura 8) nas cores de tons em vermelho que representam as maiores declividades da área como um todo $\left(36,1^{0}\right.$ a $\left.79^{\circ}\right)$. Vale ressaltar que o mapa de declividade foi classificado de acordo com a técnica de quebras naturais do histograma de distribuição da declividade pela área de estudo. Sendo assim, foram criadas nove classes que estatisticamente representam os agrupamentos mais significativos desta variável. 


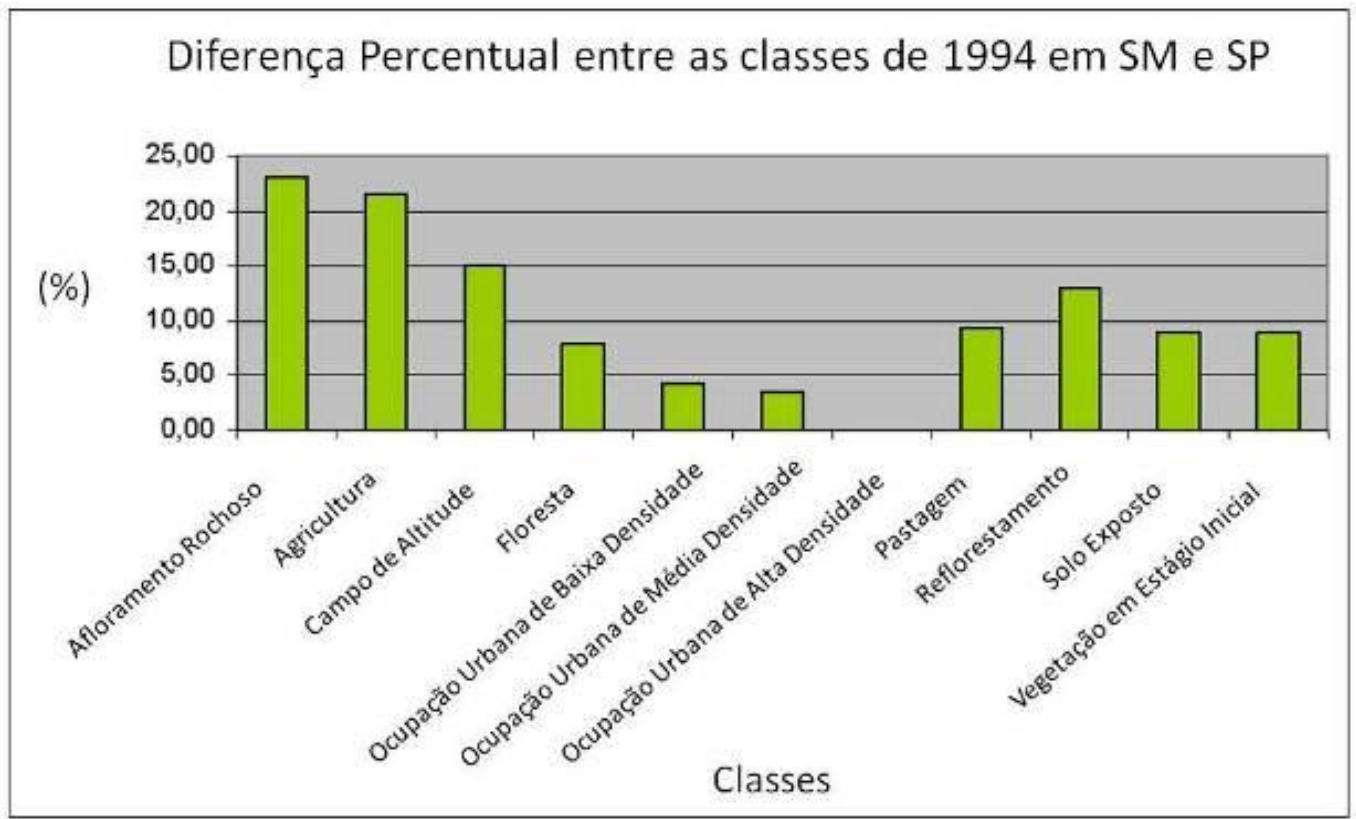

Figura 4. Diferença percentual entre as classes de 1994 em superfície modelada (SM) e planimétrica (SP). Fonte: Autoria própria.

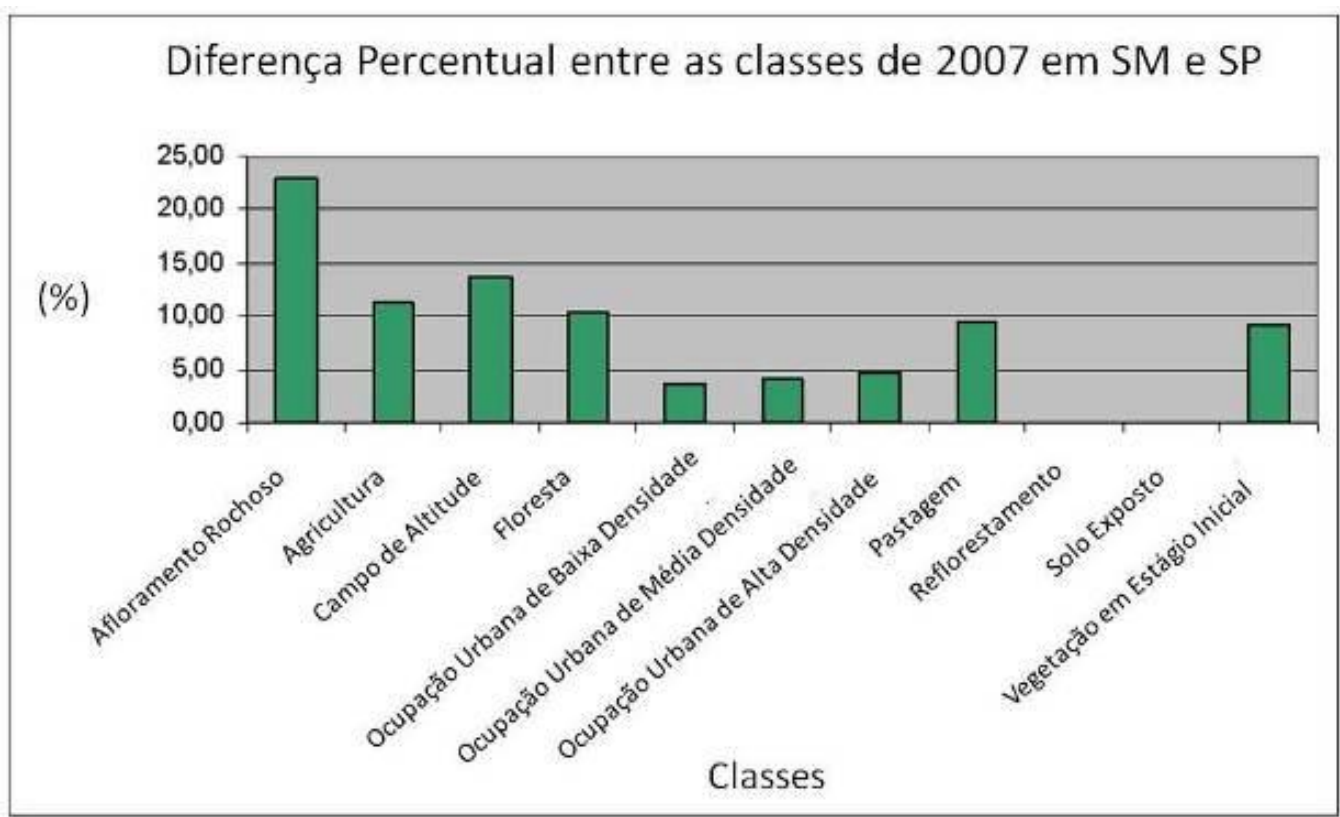

Figura 5. Diferença percentual entre as classes de 2007 em superfície modelada (SM) e planimétrica (SP). Fonte: Autoria própria. 


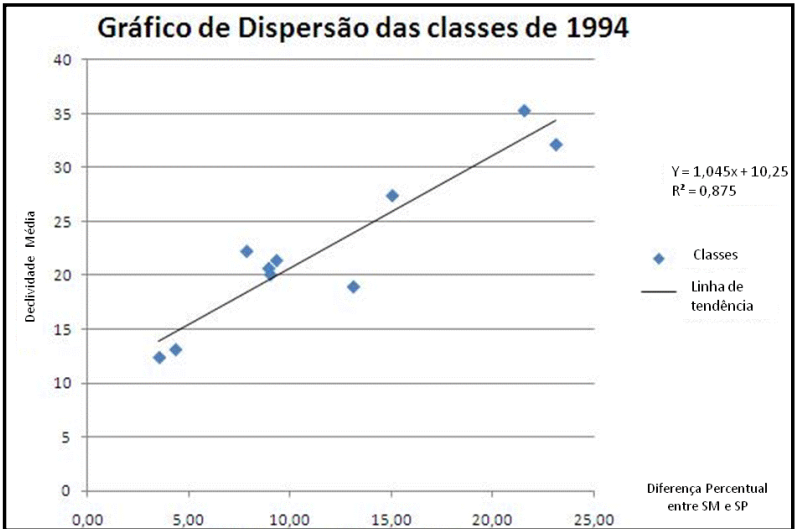

Figura 6. Gráfico de dispersão das diferenças das observações em superfície modelada (SM) e planimétrica (SP) e a declividade média das classes do mapeamento de 1994.

Fonte: Autoria própria.

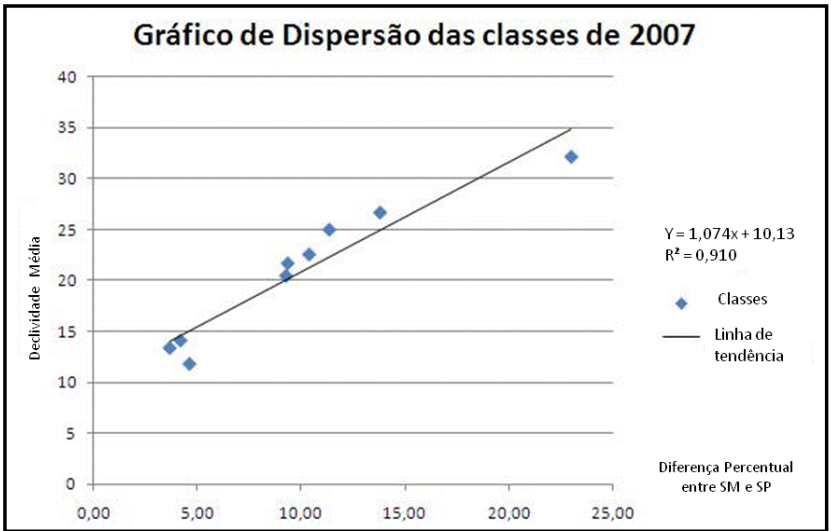

Figura 7. Gráfico de dispersão das diferenças das observações em superfície modelada (SM) e planimétrica (SP) e a declividade média das classes do mapeamento de 2007.

Fonte: Autoria própria.

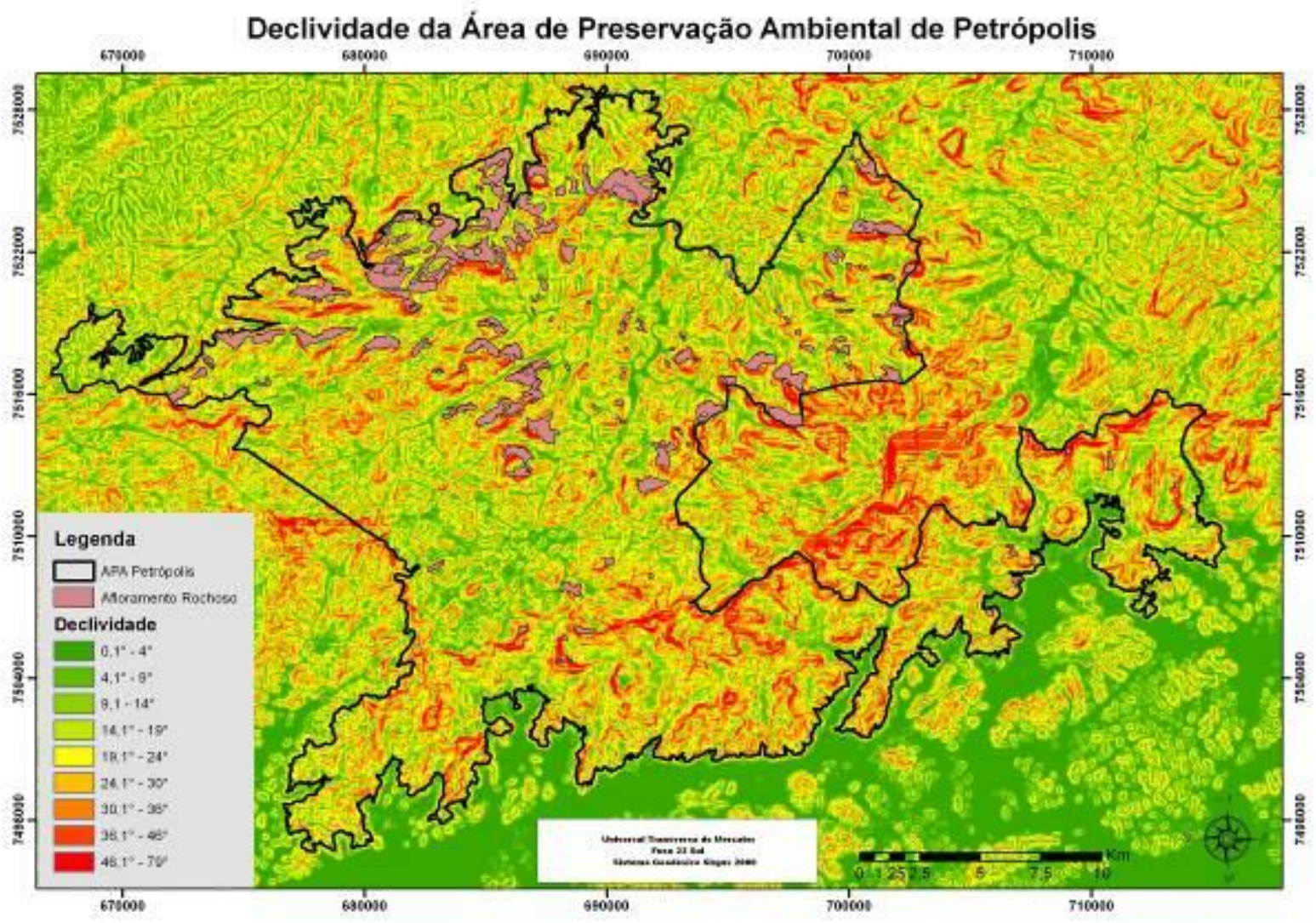

Figura 8. Mapa de Declividade e de Afloramento Rochosos da APA Petrópolis. Fonte: Autoria própria.

Em relação à dinâmica da vegetação, inicialmente, foram observadas as três classes da dinâmica e suas respectivas comparações com a superfície modelada e planimétrica. A classe Preservação apresentou 43,96 $\mathrm{km}^{2}$ de diferença entre tais superfícies, sendo a maior dentre todas, em termos absolutos. A 
segunda maior diferença foi encontrada na classe Não Vegetada, com 11,18 km² e a última, a classe retração com 4,05 km² de diferença, conforme apresentado na figura 9 . Em termos relativos, essa diferença se modifica: a maior diferença percentual é a da classe Não Vegetada, com 10,88\%, enquanto a classe de Preservação apresenta uma diferença de 9,8\%. E por fim, a classe de Retração com $8,9 \%$ de diferença percentual entre os dois tipos de observações.

A partir da classe de Retração, foi possível calcular uma taxa de retração da vegetação com base na comparação entre as observações em superfície modelada e planimétrica. Ao longo de 13 anos, de 1994 a 2007, houve uma diferença absoluta de 0,31 km²/ano $(3,49 \mathrm{~km} 2$ em Superfície Planimétrica e 3,80 km2 em Superfície Modelada), que se reflete no valor de diferença relativa de 8,16\% (figura 10).

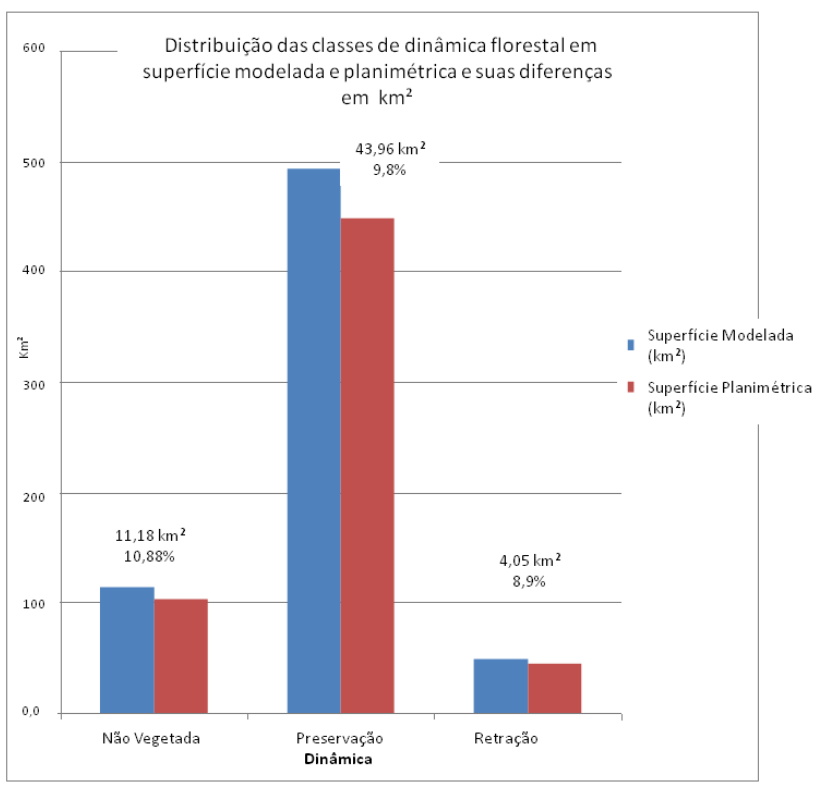

Figura 9. Distribuição das classes da dinâmica da vegetação em superfície modelada e planimétrica em valores absolutos $\left(\mathrm{km}^{2}\right)$ e relativos $(\%)$.

Fonte: Autoria própria.

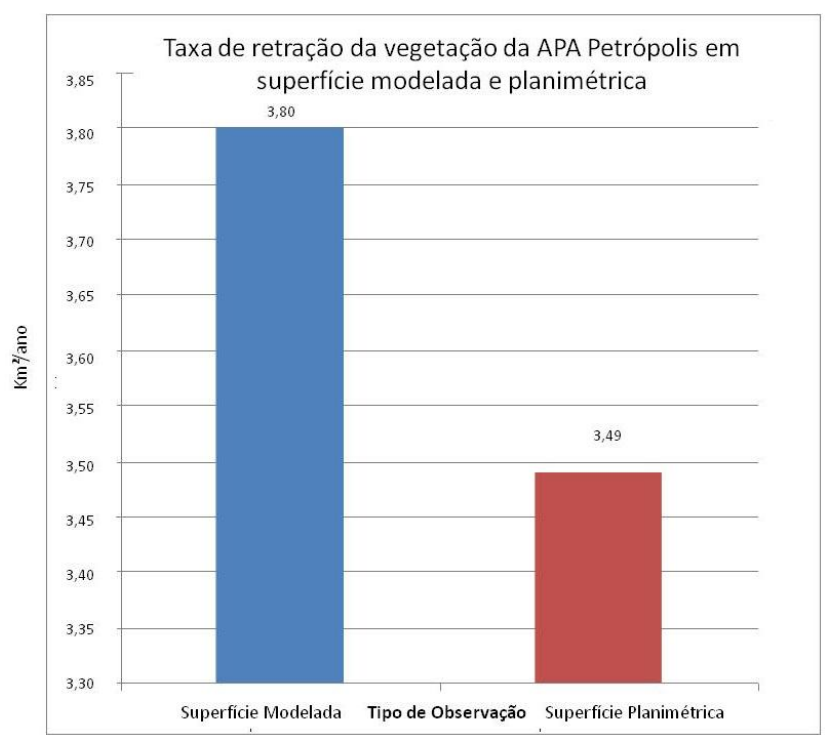

Figura 10. Taxa de retração da vegetação da APA Petrópolis entre os anos de 1994 e 2007, em superfície modelada e planimétrica $\left(\mathrm{km}^{2} / \mathrm{ano}\right)$. Fonte: Autoria própria.

Como último resultado, tem-se o mapa de dinâmica da vegetação entre 1994 e 2007, no qual a classe Preservação ocupa a maior parte da APA Petrópolis, e majoritariamente nas partes mais elevadas da área de estudo como um todo. Posteriormente, a classe Não Vegetada ocupando as áreas com menores 
declividades. Por fim, a classe Retração distribuída de forma pontual e próximas às áreas Não Vegetadas, e em direção às áreas da classe Preservação, de acordo com a figura 11.

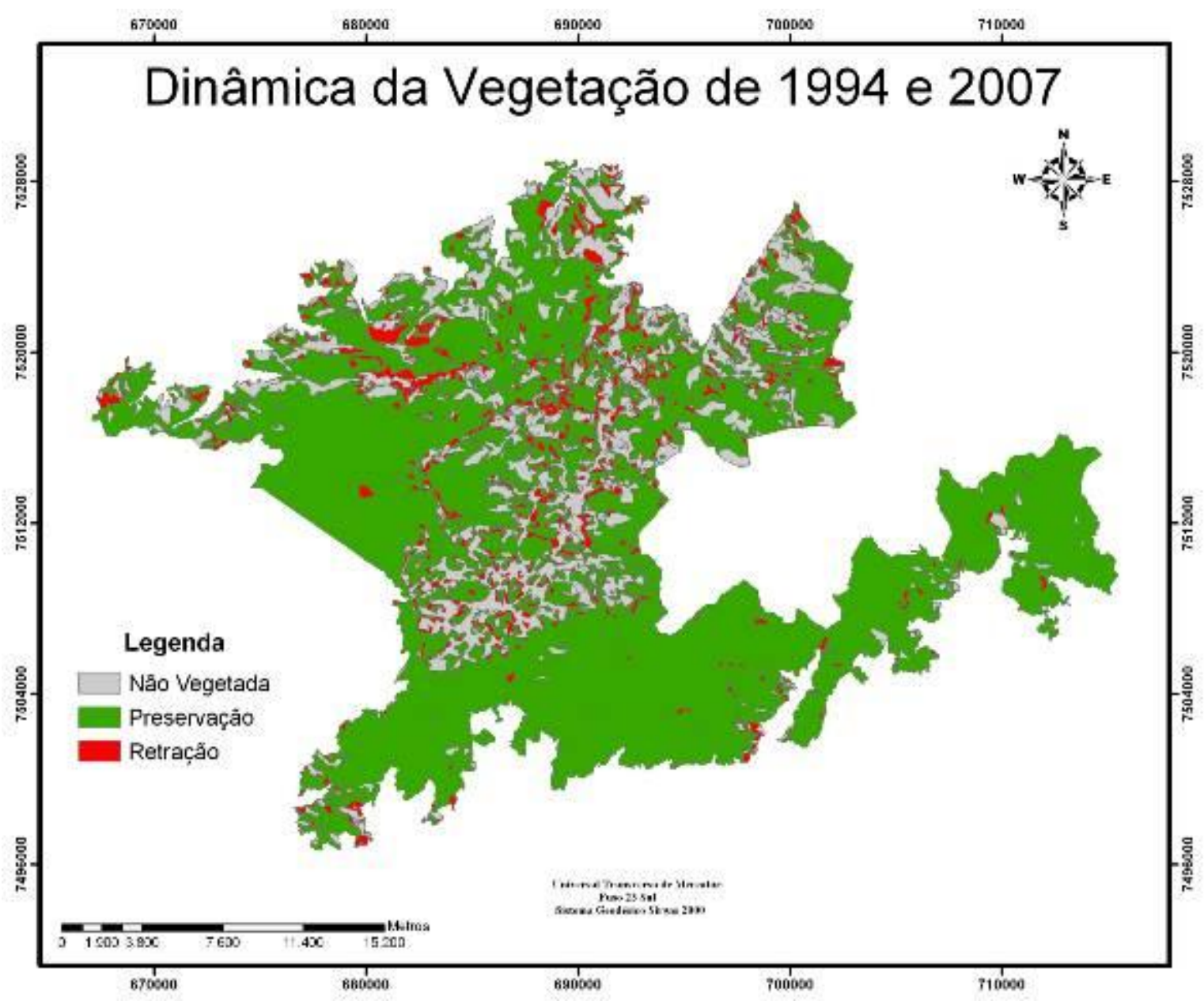

Figura 11. Mapa da dinâmica da vegetação da APA Petrópolis entre 1994 e 2007.

Fonte: Autoria própria.

\section{CONSIDERAÇÕES FINAIS}

Os resultados, de maneira geral, mostraram-se satisfatórios em relação às comparações em superfície modelada e planimétrica. Assim como já indicava a bibliografia consultada, no que tange análises que levam em consideração a rugosidade do relevo. Desta forma, as classes de cobertura e uso da terra que possuem os maiores valores de declividade apresentaram as maiores diferenças percentuais em relação às superfícies. Mais especificamente, a classe de Afloramento Rochoso apresentou as maiores diferenças, enquanto as classes localizadas nas menores declividades, como as de Ocupação Urbana, não contribuíram para ocorrência de valores discrepantes entre a superfície modelada e planimétrica. 
Em relação às análises da dinâmica da vegetação, observou-se que a classe Preservação ocupa grande parte da APA Petrópolis. Majoritariamente as áreas de Preservação se localizam nas áreas de maior declividade, cuja característica geomorfológica, baseada num relevo mais íngreme e movimentado contribua para a manutenção da floresta, e também faz com que os valores de diferença entre a superfície modelada e planimétrica se intensifiquem. A segunda de maior expressão classe é a Não Vegetada, englobando as classes de Ocupações Urbanas, Pastagem, Afloramento Rochoso e Agricultura, que fazem com que a distribuição da área total desta classe aumente. Também é a segunda maior na diferença comparativa entre as superfícies, pois apresenta a classe Afloramento Rochoso que acentua esses valores. Por fim, a classe retração é a de menor representatividade espacial, pois as áreas de transição de Preservação para Não Vegetada acontecem em áreas que dificultam a ocupação humana. Dessa forma, essa classe ocupa, predominantemente, a faixa de transição, fazendo com que não haja diferenças relevantes entre as superfícies analisadas.

A taxa de retração da vegetação ao longo dos 13 anos avaliados também ressaltou a importância das análises em superfície modelada, pois a diferença em relação à superfície planimétrica foi representativa de um incremento de 31 campos de futebol. Verifica-se, assim, que a APA Petrópolis, mesmo sendo uma área protegida por lei e com algumas restrições de ocupação, apresenta uma dinâmica da vegetação bastante intensa. Essas diferenças são acentuadas quando analisadas em superfície modelada, o que agrava mais ainda o quadro. Neste sentido, esse tipo de observação se torna de suma importância, pois permite uma avaliação mais realista da situação de dinâmica da paisagem das unidades de conservação.

\section{REFERÊNCIAS}

ABREU, Marcelo Bueno de. Análise Espaço temporal da Cobertura e Uso da Terra no Rio de Janeiro de 1994 até 2007.134 f. Dissertação (Mestrado em Geografia) - Programa de Pós-Graduação em Geografia, Instituto de Geociências, Universidade Federal do Rio de Janeiro, 2010. 
FERNANDES, Manoel do Couto. Desenvolvimento de Rotina de Obtenção de Observações em Superfície Real: Uma Aplicação em Análises Geoecológicas. 263 f. Tese (Doutorado em Geografia) - Programa de Pós-Graduação em Geografia, Instituto de Geociências, Universidade Federal do Rio de Janeiro, 2004.

FERNANDES, Manoel do Couto. Discussões conceituais e metodológicas do uso de geoprocessamento em análises geoecológicas In: BICALHO, Ana Maria de Souza Mello; Gomes, Paulo César da Costa (Orgs.). Questões metodológicas e novas temáticas na pesquisa geográfica. $1^{a}$ ed. Rio de Janeiro: Publit, 2009. 308 p. p. 280-299.

MENEZES, Paulo Marcio Leal de; FERNANDES, Manoel do Couto. 2013. Roteiro de Cartografia. v.1. São Paulo: Oficina de Textos, 2013. 288p.

Instituto Brasileiro do Meio Ambiente e dos Recursos Naturais Renováveis (IBAMA). Plano de Manejo da Área de Proteção Ambiental da Região Serrana de Petrópolis. Brasília, IBAMA, 2007. 489p. p.1-28.

MICELI, Bruna Santos; DIAS, Filipe de Meireles; SEABRA, Fernanda Moraes; SANTOS, Paulo Roberto Alves dos; FERNANDES, Manoel do Couto. Avaliação Vertical de Modelos Digitais de Elevação (MDEs) em Diferentes Configurações Topográficas para Médias e Pequenas Escalas. RBC. Revista Brasileira de Cartografia (Online), v. 63/1, março de 2011, p. 191-201.

MICELI, Bruna Santos. Avaliação de Métricas da Paisagem baseadas em Observações em Superfície Real para a Análise de Fragmentação Florestal. 130f. Dissertação (Mestrado em Geografia) - Programa de Pós-Graduação em Geografia, Instituto de Geociências, Universidade Federal do Rio de Janeiro, 2011.

Zoneamento Ecológico Econômico (ZEE). Análise e Qualificação Sócio-Ambiental do Estado do Rio de Janeiro (escala 1:100.000): subsídios ao ZEE - Zoneamento Ecológico Econômico. Relatório da Etapa VII FASE 3: Regiões Hidrográficas Baia da Ilha Grande (RH-I), Guandu (RH-II), Baia da Guanabara (RH-V) e Lagos/ São João (RH-VI). Volume 2, Rio de Janeiro: Fundação Copptec, 2009. 